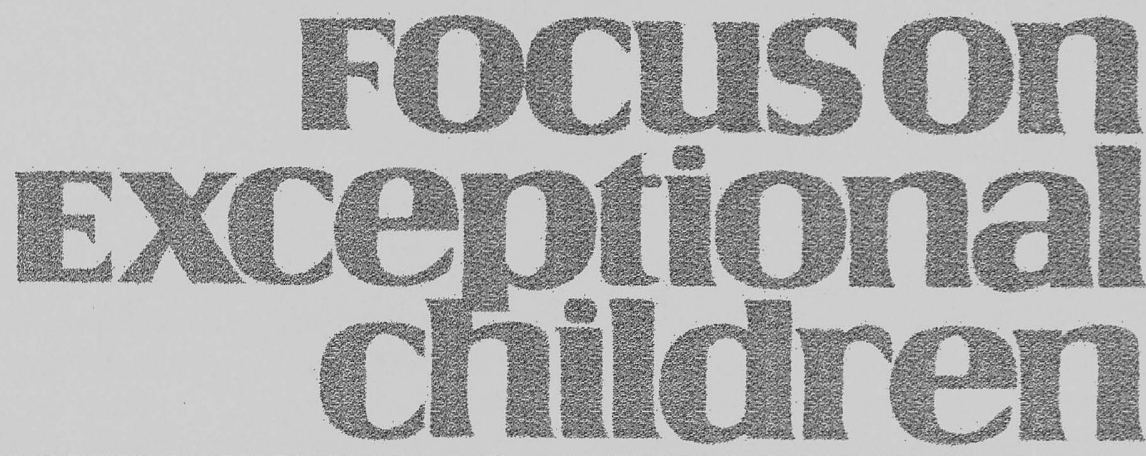

\title{
Effective Instructional Design and Delivery for Teaching Task-Specific Learning Strategies to Students with Learning Disabilities
}

\author{
Charles A. Hughes
}

This article proposes that how learning strategies are taught to students with learning disabilities (LD) is as important as the strategies themselves. Moreover, the preponderance of existing research supports an explicit approach for designing and delivering lessons for teaching students with LD to learn and use task-specific learning strategies. To frame this discussion, the article presents a general description of task-specific learning strategies as well as an explanation as to why many students with LD need instruction in this area. Next, it offers the design and content features of task-specific strategies found in existing strategy curricula, followed by a brief summary of the research on effective elements of instruction for teaching skills and strategies to students with $\mathrm{LD}$. The remainder of the article focuses on how to teach task-specific learning strategies in ways that incorporate identified effective and explicit teaching methodologies that address a number of learning characteristics associated with learning disabilities.

\section{WHAT ARE TASK-SPECIFIC LEARNING STRATEGIES?}

Learning strategies typically consist of a series of overt (observable) and covert (internal verbal) steps learners follow as they complete a specific task or solve a particular problem. In essence, a learning strategy is how a person thinks and acts when planning, executing, and evaluating performance while completing an academic task (Deshler \& Schumaker, 2006; Lenz, Ellis, \& Scanlon, 1996). To distill this further, learning strategies instruction teaches students how to learn.

Some researchers have broken learning strategies into two related processes: cognitive and metacognitive (Luke, 2006). The cognitive process component refers to the concrete, action-based activities of applying the strategy (e.g., following the steps needed to complete a task such as writing a persuasive essay), whereas metacognitive processes involve more executive, self-regulatory types of decisions (e.g., deciding which strategy is appropriate to use when writing a persuasive essay, monitoring the strategy's effectiveness, evaluating whether the essay meets the expected criteria). In sum, strategic learners (a) know what strategies are within their repertoire, (b) hypothesize which strategy is appropriate

Dr. Hughes is a professor of special education at Pennsylvania State University. 
given the task at hand, (c) remember the sequence of steps to follow and how to apply them, (d) have an outcome goal in mind, (e) evaluate whether the strategy is effective in meeting the goal and make needed adjustments if they are not meeting it, and (f) decide when the outcome goal has been reached. While successful learners have a large repertoire of effective and efficient strategies and can apply them with little effort, many students struggle to do so, especially those with LD (Deshler, Lenz, Bulgren, Schumaker, Davis, \& Grossen, 2004; Lenz et al., 1996; Reid \& Lienemann, 2006).

\section{WHY MANY STUDENTS WITH LEARNING DISABILITIES NEED EXPLICIT LEARNING STRATEGY INSTRUCTION}

Like all school-age students, students with LD are expected to acquire information, skills, and knowledge presented through a variety of formats (e.g., textbooks, lectures, audio-visual media). Additionally, students need to be able to store this knowledge and information in a way that enhances understanding and retention. Finally, students must be able

\section{FOCuson
Exceptional
children}

ISSN 0015-511X FOCUS ON EXCEPTIONAL CHILDREN (USPS 203-360) is published monthly except June, July, and August as a service to teachers, special educators, curriculum specialists, administrators, and those concerned with the special education of exceptional children. This publication is annotated and indexed by the FRIC Clearinghouse on Handicapped and Gifted Children for publication in the monthly Current Index to Joumals in Education (CIJE) and the quarterly index, Exceptional Children Fducation Resources (ECER). The full text of Focus on Exceptional Children is also available in the electronic versions of the Education Index. It is also available in microfilm from Serials Acquisitions, National Archive Publishing Company, P.O. Box 998, Ann Arbor, MI 48106-0998. Subscription rates: individual, $\$ 50$ per year; institutions, \$68 per year. Copyright (c) 2011, Love Publishing Company. All rights reserved. Reproduction in whole or part without written permission is prohibited. Printed in the United States of America. Periodical postage is paid at Denver, Colorado. POSTMASTER: Send address changes to:

$$
\begin{gathered}
\text { Love Publishing Company } \\
\text { Executive and Editorial Office } \\
\text { P.O. Box } 22353 \\
\text { Denver, Colorado } 80222 \\
\text { Telephone (303) 221-7333 }
\end{gathered}
$$

\section{CONSULTING EDITORS}

Steve Graham Vanderbilt University
Ron Nelson

University of Nebraska-Lincoln

Eva Horn

University of Kansas

Carrie E. Watterson Senior Editor
Stanley F. Love Publisher to demonstrate this knowledge via outlets such as writing research papers, taking tests, completing homework, and giving oral reports. Similar expectations extend to postschool settings, such as the workplace, where new knowledge and skills must be continually updated by using the same acquisition, storage, and expression procedures noted above. Unfortunately, a significant number of students do not exhibit the skills and strategies characteristic of successful learners.

The following are some general characteristics of many students with LD that hinder their academic success.

\section{Students with LD Often Do Not Develop or Use Effective and Efficient Strategies When Solving Tasks}

Successful learners identify specific features and require ments of a task and develop and carry out a plan for completing that task. Many struggling learners do use strategies when given a task, though either the strategies themselves or the students' application of them are often minimally effective and efficient (Deshler, Ellis, \& Lenz, 1996). For example, if students are required to memorize a list of words, some of them might examine the list to see whether the words could be categorized in some way (e.g., group the items based on semantic features or other characteristics). Some students might develop mnemonic devices such as acronyms or acrostics that assist later retrieval. Still other students may visualize pictures to help them remember content. However, some students (e.g., those with learning difficulties) merely read the list over and over again. This rereading strategy, called verbal rehearsal, is certainly a strategy for memorizing; however, it is one of the least effective and efficient of those available (Swanson \& Saez, 2003).

Another example illustrating the difficulty some students have applying effective strategies relates to studying a textbook. Successful students, when given a reading assignment and asked to study the material for later testing, read the material and highlight key passages, take notes, write short summaries, and so on. Other less strategic students often limit their studying to rereading; again, a strategy, but one of the least effective for retaining key information in the text. So the problem, as noted earlier, is not always that students with LD do not use strategies. Rather, the strategies they use are often ineffective and inefficient: They do not actively and systematically interact with information in a manner that transforms or manipulates the information, resulting in increased retention and understanding.

\section{Students with LD Often Fail to Take Advantage of Prior Knowledge When Facing New Problems or Tasks}

Successful learners make connections and generalize what they know to new situations. Specifically, they make connections between what they know and how that knowledge can be applied in the current situation. They know 
what strategies and skills are in their repertoires and can evaluate which ones are most likely to help them with immediate tasks. Less successful students may have knowledge related to the current task but do not make the connection between what they know and what they are being required to do. For example, a student may know the basic conventions of print (e.g., rules of capitalization and punctuation) but does not apply them when writing. Another example illustrating the lack of connection between prior knowledge and a new task is when a student fails to see that his or her knowledge about the reproductive cycle of a frog can be used to answer a question about the reproductive cycle of another amphibious creature (Archer \& Hughes, 2011)

\section{Students with LD Often Have Difficulty Using Importance Cues}

Successful learners distinguish the important from the unimportant by recognizing and using cues. For example, they know what to write down during a lecture and what parts of the text to study. They know that when a teacher writes something down, repeats it, or underlines it during their lecture they should write it down. Other less successful students often do not recognize these cues and approach the task of note taking by trying to take down everything the lecturer says (Hughes \& Suritsky, 1994).

To further illustrate, successful learners are aware of text structures or features such as headings and summaries and use them when studying. Students with LD, as noted earlier, may treat all information in the text as equally important. This is why, when given a highlighter and a text chapter, some students will highlight virtually the entire chapter.

\section{Students with LD Often Do Not Use Organizational Strategies for Studying and Completing Tasks}

Students with LD may exhibit a variety of problems when it comes to assignment completion (Hughes, Ruhl, Schumaker, \& Deshler, 2002). For starters, they may not understand what is expected of them and, for a number of reasons, may not seek clarification. These students often do not take the time (or know how) to analyze the assignment in terms of materials needed to complete it or to identify the major subtasks involved and their sequence. Finally, students with LD may underestimate the amount of time needed to finish a task satisfactorily.

When successful learners are assigned a research report, they spend some time thinking about necessary. steps (e.g., picking a topic, identifying sources of information, reading and taking notes, developing an outline of key ideas, executing a first draft, editing it, and producing a final product), estimating how long each substep may take, and then scheduling when they will work on it. Students with LD, in contrast, spend little time in the planning process, use minimal sources, and will execute one draft and spend minimal time in the editing process (Graham \& Harris, 2003).

In short, many students with learning difficulties have problems being active, organized, and strategic learners. The promising news is that research has shown they can be taught learning strategies that result in better learning and success in school. Over the past 25-plus years, researchers have investigated the efficacy of learning strategies instruction on the performance of students with $\mathrm{LD}$ and found overall positive outcomes. Learning strategies instruction has been found to be effective in a variety of academic areas, including (a) reading (e.g., Berkeley, 2007; Gersten, Fuchs, Williams, \& Baker, 2001), (b) math (Miller, 1996; Montague, 2008), (c) written expression (Graham \& Harris, 2003; Therrien, Hughes, Kapelski, \& Mokhtari, 2009), and (d) academically-related skills such as note taking, test taking, and assignment completion (Boyle, 2006; Hughes, 1996; Hughes et al., 2002; Suritsky \& Hughes, 1996). The next section of this article presents the content and design features of many of the taskspecific learning strategies used in the reviewed studies.

\section{CONTENT AND DESIGN FEATURES OF A TASK-SPECIFIC LEARNING STRATEGY}

The content and design features of typical learning strategies described in this section are based on several sources (Deshler et al., 1996; Ellis, Deshler, Lenz, Schumaker, \& Clark, 1991; Deshler \& Schumaker, 2006; Ellis \& Lenz, 1987). The content features of a learning strategy relate to the steps of a strategy and how the mental and physical actions are used to complete an academic task, that is, how the strategy incorporates features that facilitate an effective and efficient response to an academic expectation or task. Design features relate to the way the strategy is packaged for presentation to the students. The manner in which a strategy is organized and arranged for instruction should lead to optimal student learning and use. To provide a context for this description of content and design features, a sample strategy is used (see Figure 1). The Assignment Completion Strategy (Hughes, Ruhl, Schumaker, \& Deshler, 1995, Hughes et al., 2002) is an organizational strategy used to increase the frequency and quality of completed homework.

\section{Content Features}

Content features of a strategy typically include the following:

Steps that are sequential and lead to a specific and successful outcome. A learning strategy consists of a set of steps that helps initiate and organize students' approach to a task and results in its successful completion. The set of steps included in the Assignment Completion Strategy represents a sequence of actions used during the homework completion 


\section{$P$ repare your plan}

$\mathbf{R}$ ecord and ask

O rganize

J ump to it

E ngage in the work

C heck the work

T urn it in
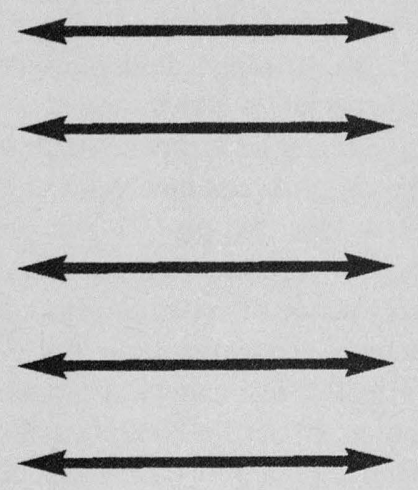

\section{5.} her understanding of assignment requirements (Self-questioning)

6. Cues learner to check and correct his or her work (Self-monitoring and evaluation)

7. Cues learner to submit work on time and record completion (Self-monitoring strategy)

FIGURE 1.

Components of Assignment Completion Strategy

process that, if followed, results in turning in a quality assignment on time.

Steps that cue students to use specific cognitive and metacognitive skills. Figure 1 includes cognitive and metacognitive processes used during each step of the Assignment Completion Strategy. As mentioned earlier, strategies include executive, self-regulatory processes such as selfinstruction, self-questioning, plan development, goal setting, and self-monitoring. It is the existence of these processes that make strategies strategic rather than simple procedures.

Steps that cue students to take an overt action. A strategy must cue both mental and physical actions. Most strategies require students to do something that results in a permanent product that can later be evaluated for accuracy. For example, in the Organize step of the Assignment Completion Strategy, students are required to write several parts of their homework plan on a form (e.g., how many major components are included in the task, how many study sessions it will take to complete the components, when they will work on completing the assignment). Without physical actions, permanent products, or both, it would be difficult for teachers to evaluate whether and how well the student is applying the strategy and provide corrective feedback.

\section{Design Features}

Design features of a learning strategy typically include the following:
Steps that form a mnemonic device. Because many students with LD have memory problems (Swanson \& Siegel, 2001), design of the strategy should facilitate memorization of the steps. To that end, many strategies are designed so that the first letters of each step form a word (usually a word associated with the task for which the strategy is used) to help the students remember the steps. In the case of the Assignment Completion Strategy, strategy steps form the first-letter mnemonic, PROJECT. Students refer to this word when trying to remember which step (i.e., action) they should be performing. While some strategies, because of the nature of the task, can be implemented in a straight sequence, other strategies will require repetition of some of the steps during the completion of the task.

Steps that contain few words. Again, to address memory problems, strategy steps should not contain unnecessary words. Each step contains only a few words to facilitate direct association to the cognitive and physical actions necessary to perform the step. Notice that the steps of the Assignment Completion Strategy include only a few words (e.g., Prepare your plan, Record and ask, Organize). Obviously, the process of carrying out each step is more complex than a few words can adequately address, but detailed information is introduced when the strategy is actually taught. The steps themselves are used to cue more detailed overt and covert behaviors.

Steps that begin with a verb. Steps of the strategy cue the student to do something. Thus, it is more powerful to begin 
the step with a verb or action word than another part of speech. Accordingly, the first words in the steps of the Assignment Completion Strategy include verbs such as "Prepare," "Record," "Organize," and so on.

A final consideration related to the content and design of a learning strategy deals with its usefulness. To that end, the learning strategies selected for instruction should address tasks with which students have the most difficulty, that occur frequently and over an extended amount of time, and those that can be applied across a variety of settings, situations, and contexts.

To summarize, many students with LD can benefit from using well-designed, effective, and efficient task-specific learning strategies to help them become more independent and successful learners. Over the past few decades, a number of researchers in the LD field have developed a variety of task-specific learning strategies that reflect the content and design features described above (e.g., Deshler et al., 1996; Graham \& Harris, 2003). However, another key component of a learning strategy approach goes beyond what the strategy looks like. The other integral part is how it is taught, that is, how to teach the strategies effectively so students acquire, maintain, and generalize them. Teachers can teach strategies with outstanding content and design features; however, if the instructional procedures and processes are not effective, their efforts will be minimized. Thus, how a task-specific strategy is taught can be seen as important as the strategy itself.

\section{RESEARCH ON EFFECTIVE INSTRUCTION}

\section{FOR STUDENTS WITH LEARNING DISABILITIES: A BRIEF REVIEW}

When beginning a discussion of how to teach, a frequently asked question is, "What is the best and most effective way to teach strategies (or anything else)?" Obviously, that question has been debated, often heatedly, for as long as there have been students and teachers. This section will focus on the research (versus philosophy) related to effective instruction for students with LD as well as students labeled low achieving or at risk. While it is folly to state with certainty that there is always one best way to teach academic skills and strategies to all students with $\mathrm{LD}$, the preponderance of evidence for teaching students with $L D$ how to perform tasks (such as apply task-specific strategies) points to a direct, explicit, and guided approach to instruction.

Over the past 40 or so years, a variety of studies have been carried out to attempt to identify teacher instructional behaviors that positively impact student achievement and learning - for both general and special education students. While it is not the purpose of this section to provide a detailed analysis of the effective instruction research, (see Archer \& Hughes, 2011, for an expanded description of this research), it is briefly summarized here to provide the background and rationale for the rest of the article, the focus of which is on how elements of explicit instruction (EI) are incorporated in the design and delivery of lessons used to teach task-specific learning strategies to students with LD.

Brophy and Good (1986) reviewed dozens of studies published from 1973 to 1983 that examined the link between teacher instructional behaviors and student achievement. Based on their review, they identified some overarching variables strongly associated with student achievement. They found that classroom instruction needed to keep students engaged on academic tasks at a high level of success and be focused on increasing the amount of content covered. The elements they identified that supported these principles included structuring information to be taught in a logical and clear fashion, presenting clear demonstrations followed by practice, closely monitoring student performance while they practiced, and providing timely corrective feedback. They also found drill and practice to be highly beneficial for building fluency and retention. One major finding was that, while most students learned better when teachers addressed these principles by incorporating elements of direct and explicit instruction, the students who benefitted most were students characterized as low achievers.

One of the largest countrywide educational research efforts, Project Follow-Through, was conducted in the 1960s and 1970s. The major purpose of this governmentfunded study was to compare the effectiveness (i.e., impact on student achievement) of 12 instructional programs that were categorized as one of three models: basic skills, cognitive-conceptual, or affective-cognitive. The model that had the largest impact was Direct Instruction (DI), a curriculum that contains explicit elements of instruction (e.g., breaking down tasks, logical sequence of presenting tasks, providing clear models, practice with feedback, distributed practice; see Adams \& Engelmann, 1996, for a description of DI as well as Project Follow-Through). Again, this type of instructional approach was effective with many students, both high and low achievers; however, students who were struggling academically benefitted the most.

More recently, several reports sponsored through the US Department of Education identified EI, as a well-supported approach. For example, in 2008 the National Mathematics Advisory Panel concluded that EI has consistently resulted in improving the math performance of low-achieving students, both in calculation and problem solving. Kamil et al. (2008) examined studies of teaching adolescent literacy skills and strategies and concluded that EI had the strongest level of support for teaching both vocabulary and reading comprehension. Gersten et al. (2009) rated the evidence for using EI procedures to teach math skills and problem-solving strategies to struggling students as strong. Finally, Hattie (2009) conducted a meta-analysis of over 800 meta-analyses 
of studies of instructional methodologies and their relationship to student achievement. One of his findings was that many of the elements of an explicit approach, such as guided and distributed practice, teacher clarity and explicitness, building commitment to learn, mastery learning, and providing corrective feedback, had medium to high effect sizes.

Turning to research in special education, specifically LD, a number of syntheses of classroom research were published in the 1990s and 2000s (e.g., Gersten et al., 1998; Kroesbergen \& Van Luit, 2003; Mastropieri, Scruggs, Bakken, \& Whedon, 1996; Vaughn, Gersten, \& Chard, 2000), all of which came to a similar conclusion: An explicit and direct approach to teaching students with $\mathrm{LD}$ academic skills and strategies is usually the most effective method.

Finally, Lee Swanson and his colleagues (e.g. Swanson, 1999, 2001; Swanson \& Hoskyn, 1998) conducted several meta-analyses of 180 interventions studies with students with LD and identified the instructional behaviors most associated with positive outcomes. These findings yielded similar findings to all of the above studies: Explicit instructional elements, such as skill sequencing, breaking down complex skills for instruction, modeling, multiple practice attempts with corrective feedback, controlling task difficulty, and requiring frequent student responses, help students learn.

In summary, the use of EI elements has a long history of support for teaching a variety of academic skills and strategies, especially for those students with learning difficulties. The elements of EI in the mentioned studies and which are closely associated with learning strategy instruction are the following:

1. Break down multi-step strategies for initial instruction.

2. Establish relevance to increase motivation and commitment to learn the strategy.

3. Review and verify previous prerequisite learning.

4. Build in multiple opportunities for students to respond in order to increase engagement.

5. Provide clear, concise, and consistent models or think-alouds.

6. Provide guided and scaffolded practice to promote success and confidence.

7. Provide timely corrective feedback.

8. Require memorization and understanding of strategy steps.

9. Include goal setting and self-monitoring.

10. Provide opportunities for authentic and distributed practice.

11. Provide opportunities for, and cue, strategy generalization across tasks and settings; and provide opportunities for, and cue, maintenance.
These elements address many of the difficulties that students with LD exhibit in school, including problems with working memory, retention, motivation, attention, and self-regulation.

The question now becomes, "How does a teacher design instruction to teach students task-specific strategies that incorporate many or all of the elements of EI?" In the next section, the general stages of instruction employed in the most frequently used strategy curricula are described.

\section{HOW TO EXPLICITLY TEACH LEARNING STRATEGIES}

The content of this section is based largely on two similar models of learning strategy instruction that have incorporated the elements of effective instruction described earlier: the Strategic Intervention Model (SIM) developed by Don Deshler and Jean Schumaker and their colleagues at the University of Kansas Center for Research on Learning (e.g., Berry, Hall, \& Gildroy, 2004; Deshler \& Schumaker, 2006; Deshler et al., 1996; Lenz et al., 1996) and the Self-Regulated Strategy Development (SRSD) program developed by Steve Graham and Karen Harris of Vanderbilt University (formerly of the University of Maryland) and their colleagues (e.g., Graham \& Harris, 2003; Harris, Graham, Mason \& Friedlander, 2008; Reid \& Lienemann, 2006). Over the last several decades, both programs have developed and validated numerous task-specific strategies for use with students with LD. The SIM curriculum includes a wide range of strategies (e.g., reading, math, writing, memory, test taking, assignment completion), while the SRSD program focuses primarily on writing strategies (Luke, 2006). Researchers from both programs have developed somewhat similar instructional procedures or stages of learning strategy instruction that incorporate many of the elements of EI.

\section{Stages of Strategy Instruction}

In keeping with the frequent use of first-letter mnemonics in strategy instruction, the first-letter mnemonic STRATEGY (Figure 2) was developed to help remember commonly included instructional procedures for teaching strategies. Both SIM and SRSD have their own, albeit similar, instructional stages (SIM has eight stages and SRSD has six), and the majority of them are incorporated in STRATEGY.

In order to help illustrate and provide a context for describing the instructional stages included in STRATEGY, The Paraphrasing Strategy (Schumaker, Denton, \& Deshler, 1984) from the SIM program is used. This strategy was selected because it has only three steps and thus makes explanation more efficient. The Paraphrasing Strategy is a reading comprehension strategy for which the steps and cognitive components are presented in Figure 3. Notice that the first letters of the steps form the mnemonic, RAP. The RAP steps require students to read a passage one paragraph at a time, after 
After assessing the need to teach the strategy and teaching important prerequisites:

\section{Set the stage for learning}

Talk about why, when, \& where

Reveal strategy steps

Act out strategy steps

Teach understanding and memorization

Encourage initial practice

Give advanced practice

Yoke strategy to new situations

\section{FIGURE 2. \\ Instructional Stages for Teaching a Learning Strategy}

reading the paragraph to stop and identify the main idea along with two supporting details, and then put main idea and details into their own words. Before describing instructional stages for how to teach a learning strategy, the two initial preconditions in Figure 2 need to be addressed. That is, assessing the need to teach the strategy and whether to preteach prerequisite skills before or during strategy instruction.

\section{Assess the Need for Teaching the Strategy and Teach Prerequisites if Necessary}

As mentioned earlier, prior to teaching a strategy it makes sense to find out whether students need to learn it. Typically, two levels of assessment can be conducted: (a) how students are currently performing in the academic skill area and (b) whether they already know how to use the strategy. In the case of the Paraphrasing Strategy, current level of performance in reading comprehension should be established. This can be done informally (e.g., teacher assessment of study ability) or more systematically by checking student performance on standardized tests. In addition, teachers can conduct an assessment by requiring students to read a passage written at their current grade level (e.g., from a textbook in one of their classes) and then answer comprehension questions. This latter method has the advantage of establishing a baseline for comparison after the student has learned to use the strategy. Typically, some performance criterion level is established to help decide whether the student has problems with reading comprehension. In the Paraphrasing Strategy, students must answer at least $70 \%$ of the comprehension questions accurately to meet mastery criterion.
$R=$ Read $a$ paragraph

$A=$ Ask yourself, "What were the main idea and details in this paragraph?"

$\mathrm{P}=\mathrm{Put}$ the main idea and details into your own words

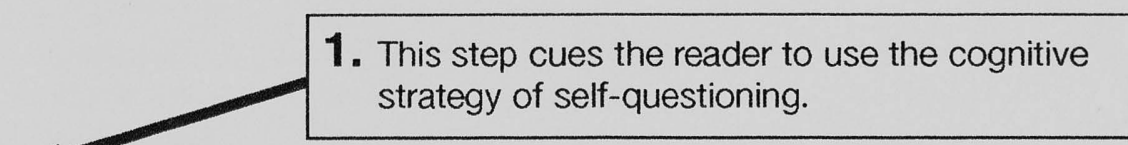

2. This step cues the reader to relationally organize the information and decide what is important and unimportant.

3. This step cues the reader to use a transformational cognitive strategy (paraphrasing) to elaborate on the information from the paragraph.

4. This step elicits an overt response that can be evaluated and on which corrective feedback can be provided. 
The second form of pretest assessment is used to establish whether students can perform the strategy itself. For the RAP strategy, students are assessed on their ability to identify main ideas and details in a paragraph and then put them into their own words. Students must score $80 \%$ or above on the quality of their paraphrases in order to reach mastery criterion.

As with assessing the need to teach any strategy, if students do not reach mastery for both assessments, they can be deemed good candidates for instruction. However, it may be the case that students who score very low on comprehension measures are having significant problems reading at the word level, and it is best to focus instruction on these skills (e.g., word identification, fluency) rather than on a comprehension strategy. If students reach or exceed mastery on both measures, instruction in the strategy is unwarranted. The decision about whether to teach the strategy becomes more complicated when a student meets mastery on one assessment and not the other. For example, if a student does not appear to have reading comprehension difficulties in grade level passages but cannot identify and paraphrase main ideas and details, the teacher would need to rely on knowledge of the student to make the decision whether to teach the RAP strategy.

Once the need for instruction is established, the strategy steps should be analyzed to identify key skills required to decide whether any prerequisite skills need to be taught prior to strategy instruction. When analyzing the RAP strategy, it appears that key skills include knowledge about what main ideas and details are as well as how to identify and decide what a supporting detail for that main idea is. The decision about whether to teach any of these skills prior to or during strategy instruction depends on knowledge of students. Some students may be able to handle learning about main ideas and details during instruction, while others may benefit from having this knowledge before learning the strategy. When the need for teaching a strategy and whether to teach prerequisites ahead of time has been established, it is time to teach the strategy.

\section{Teaching the Strategy: Generic Stages of Instruction}

The first two stages Set the stage for learning and Talk about why, when, \& where are designed to establish need and motivation to learn the strategy, provide a brief overview of the strategy, and identify where and when it can be used. The next two stages Reveal the strategy steps and Act out the strategy steps provide the core instructional procedures of describing the strategy steps in detail and modeling them through think-aloud procedures.

The next stage Teach understanding and memorization includes activities to help students memorize the strategy steps and understand why they are using them. The subsequent stages Encourage initial practice and Give advanced practice require students first to practice the strategy with materials in which the difficulty level has been reduced or controlled in some way and then to practice on more difficult materials. Finally, Yoke the strategy to new situations requires students to participate in activities that promote generalization of strategy use in settings other than the one in which they were taught. Often generalization is left until the end of instruction (e.g., after students acquire strategy use). While it makes sense to have a strong generalization component as the last stage, it is important to note that generalization procedures should be infused early, often, and throughout instruction.

These instructional stages should be viewed as fluid. That is, some strategy programs may fold the pretest into setting the stage activities, while others may combine the describing and modeling stages into one lesson. They key idea here is that regardless of the strategy program used (e.g., SIM, SRSD) or how the stages are packaged or combined in a lesson, the instructional activities included in STRATEGY need to occur to ensure students with learning difficulties acquire and generalize the strategy.

Finally, it is important for each lesson or instructional session (regardless of the stage being taught) to begin with an advanced organizer that includes (a) a review of key content from previous lessons, (b) an explanation of what will be covered in the current lesson and a rationale for learning it, (c) how the new information links with previous information, and (d) the expectations for the students: all the effective components of opening a lesson (Archer \& Hughes, 2011; Ellis \& Worthington, 1994; Hattie, 2009).

\section{Description of the STRATEGY Instructional Stages}

Set the stage for learning. After collecting pretest data or information establishing student difficulty with a particular academic demand (e.g., reading comprehension, essay writing, note taking), the teacher meets with students to discuss their current level of performance. As part of that discussion, the teacher elicits from his or her students what kinds of problems they are having related to the demand or skill, why they have problems, and how they are currently approaching the task. For example, if teaching the RAP strategy, the stage could be set by asking students to identify where and why they are having problems with reading their textbooks for understanding and retention. As students provide responses (e.g., I can't read some of the important words; I can read it, but I can't remember it after I read it), this information is written down on the board or overhead.

After that discussion, students are asked about their current approaches to reading for understanding and memory. Responses might include, "I ask someone about what the word means," "I try to read it twice," and so on. Once students are finished sharing, the teacher can begin to develop the rationale for learning the strategy. This can be done by briefly describing the strategy and explaining how it will help with the academic demand, address their current 
difficulties, and provide a more effective approach than they are currently using. For example, the teacher might say:

\begin{abstract}
It appears from the pretest that sometimes you have difficulty understanding and remembering what you read. Based on our discussion, it sounds as if some of your difficulty is due to [insert student-generated difficulties]. It also sounds like you are using strategies; however, these strategies often depend on others for help and usually don't involve manipulating or transforming the information in a personal way.
\end{abstract}

At that point, the new strategy is briefly introduced and an explanation of how it can help them is provided. Using RAP as an example, the strategy is presented as a way to help them learn to comprehend more independently and remember reading content by transforming it in ways that are more personalized. For example:

\begin{abstract}
I know of a reading comprehension strategy that many students like yourselves have learned, and it has helped them a lot. This strategy teaches you how to read one paragraph at a time, identify the important information in the paragraph, and then put the information into your own words to make it more personalized. How do you think that making the information more personal by putting it into your own words will help you understand and remember it?
\end{abstract}

This stage typically concludes with obtaining student commitment to learn the strategy. In the SIM model, the teacher begins by making a commitment to the students to do his or her best to teach the strategy, followed by obtaining written student commitment to learn the strategy.

Talk about why, when, \& where. This step continues the process of strengthening student commitment and motivation to learn the strategy by describing more specifically how learning the strategy will benefit them and the situations in which the strategy can be used. This stage begins with discussing rationales for using the strategy. For example:

\footnotetext{
Remember, this strategy will help you put what you read into your own words-it's sort of like translating information. Doing this will help you understand and remember what you read. How do you think this will help you in your classes?
}

Next, the teacher discusses and elicits situations about where the strategy can be used. For example:

\footnotetext{
What are some situations where it might be useful or important to understand and remember written information?
}

Under teacher direction, this discussion can move into strategy use in settings other than school (e.g., community, home, work). In addition to helping students understand how and where the strategy can help them, this discussion also promotes later generalization of the strategy. If available, research results are shared so that students can see the level of improvement they can expect. In the RAP strategy, students are presented a "before and after" chart that displays average baseline performance (i.e., $48 \%$ correct) compared to the average performance on a comprehension post-test (i.e., $84 \%$ correct).

Reveal the strategy steps. The major purpose of this stage is to reveal the steps of the strategy to students by describing them as well as providing rationales for their use. While this stage involves a fair amount of teacher presentation, it is also important to keep students involved by frequently asking questions to verify understanding. Essentially, each of the strategy steps is described and elaborated (what overt and covert behaviors are being cued by each strategy step), and a rationale is provided for why the step is done that way. At the end of this stage, the mnemonic device for remembering the strategy steps (e.g., RAP) are introduced. To illustrate how strategy steps can be described, a brief excerpt from the Paraphrasing Strategy Instructors' Manual (Schumaker et al., 1984) is presented in Figure 4.

Act out the strategy steps. In this stage, the purpose is to use think-aloud procedures to model how to use the strategy steps from start to finish. The modeling process involves both saying and doing. The strategy is modeled exactly the way students will be expected to perform the strategy when they begin to practice and includes concurrently verbalizing the cognitive and metacognitive aspects of the strategy (e.g., self-questioning, self-instructing, selfmonitoring). Thus, the language used when modeling selfverbalization should be matched to students' verbal styles and level. It is also important that the model appear natural, so teachers should practice the model several times before presenting this step to students. As with any other academic skill, the model is performed clearly, concisely, and consistently (Archer \& Hughes, 2011).

After the strategy steps have been modeled once, the teacher begins to enlist student assistance in the modeling process by asking them questions such as, "What is the next step?" "What do I ask myself now?" "How do I do the next part of the step?" and so on. Teachers should also begin to check student understanding by asking why questions, such as, "Why did I do it this way?" or "Why is it important to put things in your own words?" Before teachers can realistically expect students to answer these why questions, they need to have incorporated the answers in their think-alouds. For example, "The third step of the Paraphrasing Strategy is to put the main idea and details of the paragraph into my own words. I do that because putting things in my own words makes the information more personal and meaningful, which helps me remember and understand it." In addition to verifying understanding and keeping students involved, student enlistment during the model also offers the teacher opportunities to shape, expand, and correct student responses. A partial model of the Paraphrasing Strategy is shown in Figure 5.

After the model is completed and students begin to respond accurately to questions, it is time to move to the 
The bolded type below is information presented to students as cue cards and/or displayed onscreen by a projector. Unbolded type refers to what the teacher says as he or she describes the steps and actions. The text below is a partial excerpt (focusing only on part of the " $A$ " step in RAP) and is presented to illustrate the Reveal the steps stage of strategy instruction.

\section{Step 2: Ask yourself, "What were the main ideas and details of this paragraph?"}

At the end of a paragraph, ask yourself what were the main ideas and details in this paragraph. This is a self-questioning step. You ask yourself this question to cue yourself to think about and review what you just read. To review, you need to look quickly back over the paragraph and find the main idea and details

Define the main idea. Who can tell me what the main idea of a paragraph is?

That's right, it is the general subject or topic covered in the paragraph.

Define the details. Who can tell me what the details in a paragraph are?

Correct. The details are bits or pieces of information that are related to the main idea.

Describe how to locate the main idea. To locate the main idea, you will need to ask yourself some questions and look through the paragraph. The first question you should ask yourself is "What is this paragraph about?"

You should answer this question with this statement: This paragraph is about

Then ask yourself, what does it tell me about ?

You should answer this question with this statement: It tells me

Note: The teacher then goes on to describe how to identify the main idea (i.e., Look in the first sentence of the paragraph, Look for word repetitions).

\section{FIGURE 4. \\ Excerpt from the Describe Stage of the Paraphrasing Strategy}

next instructional stage. In a typical explicit lesson, prompted or scaffolded practice follows the model (Archer \& Hughes, 2011). For EI in task-specific learning strategies, an additional stage is often inserted between modeling and guided practice.
The partial model below, designed to illustrate key components of modeling, is based on a fictitious passage. To begin the model of the Paraphrasing Strategy, the teacher puts a reading selection of 4-5 paragraphs on the overhead.

Now that I have described the Paraphrasing Strategy steps and their purposes, I am going to demonstrate how to use them. As I use the strategy, I will be telling you what I am thinking. Please pay close attention because this is what I want you to be able to do pretty soon-only you will do your thinking in your head! Also, I will be asking you questions as we go through this passage so be ready to answer questions!

To remember the first step of the strategy, I think of RAP. The R step is Read a paragraph so that is what I will do. [Teacher reads the first paragraph out loud.] Okay, now I stop and do the A step in RAP which is Ask myself what are the main ideas and details in the paragraph.

I remember that I need to find the main idea first and that I have a question I can answer to help me. The first question is, "What is the paragraph about?" Answering this question will help me identify the main idea. I look at the first sentence, which is often the topic sentence, and I see it says . I see that a word(s) in the first sentence, , is used in other parts of the paragraph, so I think this paragraph is about

Now I need to identify some details about ask myself, "What does it tell me about by looking at the paragraph that it tells me about So the details are

So to summarize, this paragraph is about and some details are

What I have done is take this paragraph and found the important parts of it. I don't have to remember everything about the paragraph now, just these key things. This will be easier for me to remember!

Now I do the P step, Put the main idea and details in my own words. Putting this information in my own words will make it more personal and easier to remember.

So using some different words from those in the paragraph, I can say that this paragraph is about and some examples or details about are

During the next model of using RAP on a paragraph, the teacher begins to enlist student participation by asking questions such as, "What is the first step of RAP?" "What is the next step?" "What question do I ask myself first?" "How does it help to put the main idea and details in my own words?"

FIGURE 5.

Example of Modeling (Acting out) the Paraphrasing Strategy 


\section{Teach Understanding and Memorization}

After acting out or modeling the strategy, the next instructional stage is to ensure students memorize the strategy steps as well as understand the rationale for why the steps are important. Recalling the steps in a fluent manner will help students as they begin to practice the strategystudents will not have to stop and try to remember the steps to follow or questions to ask themselves and can therefore focus on applying the strategy.

To help students memorize the strategy steps, the SIM model often incorporates a rapid-fire verbal rehearsal exercise. For the Paraphrasing Strategy, the teacher writes the three steps of the strategy in their entirety on the board or overhead and instructs students to read the next step when she points to it. After a couple of rounds, the teacher erases a word or two from the end of each step and repeats the exercise. When students are responding correctly, more words are erased (how many words and at what point during the exercise will depend on knowledge of students and how well they are performing). This cycle is completed when the steps are erased altogether and students can state the steps accurately with no prompts.

To ensure student understanding of what to do and why they are doing it, the SIM program includes a verbal elaboration exercise in this stage. This exercise is basically a question and answer session and provides more opportunity for the teacher to correct, expand on, and promote elaboration of student responses. Questions for the Paraphrasing Strategy might include:

What is the purpose of the Paraphrasing Strategy?

Why is it helpful to reorganize information and put it into your own words?

In your own words, tell me what you do as you use the steps of the Paraphrasing Strategy?

Why is it important to ask yourself questions as you use the strategy?

What is the purpose of the last step of the strategy?

Once memorization and verbal elaboration activities have been conducted, the teacher verifies mastery by testing student ability to fluently say the steps and answer key questions without prompting. After demonstrating that they can do this, students are ready to practice using the strategy.

Encourage initial practice. The purpose of initial and scaffolded practice activities is to provide students opportunities to become successful and confident users of the strategy. It is important to support or scaffold initial practice by controlling the difficulty of the practice activities so that students experience success using the strategy. At this stage, scaffolding is critical because students are novice users of the relatively sophisticated strategy. Thus, the difficulty level of the context in which they begin to practice needs to be controlled in order to promote success.

To illustrate, think about how many people first learn to drive a car. There were a number of new skills to remember and apply as they began to practice: starting the car, pushing in the clutch, engaging the transmission, letting the clutch out while simultaneously pushing down on the gas pedal, using the turn signal, braking, and so on. And where did they go to practice? Probably to a parking lot where there were no other cars and the driving space was wide open. In essence their instructor or parent was controlling the difficulty of the task so they could focus on using their new skills without the distraction of oncoming cars.

Initial strategy practice can be scaffolded in several ways, including the following:

1. Using easier material. As mentioned above, a frequent way practice is scaffolded is by having the students apply the strategy in tasks where difficulty is controlled. For example, because the Paraphrasing Strategy is a reading comprehension strategy, students initially practice it using reading passages that are at or below their reading level. This way, the difficulty of the reading material does not interfere with practicing the new strategy.

2. Practicing parts of the strategy rather than the entire strategy. For example, students practice the first one or two steps of the strategy to mastery and then move to the next step or two, and so on, until they are practicing the strategy in its entirety. In the case of the Assignment Completion Strategy mentioned earlier, students would practice the first three steps (PRO) to mastery using teacher-provided information (e.g., simulated assignments versus actual assignments) before moving on to the other steps. If this method is used, it is important to make practice cumulative by including practice in the first few steps when students begin to practice the rest of the strategy so that the steps build on each other.

3. Providing visual prompts. During initial practice, posters that display strategy steps (e.g., the RAP steps) as well as key self-questions (e.g., Ask yourself, "What is this paragraph about?") to cue strategy use. Students can also create personal cue cards to help remind them about what to do as they practice the strategy.

4. Providing high levels of assistance. When students begin to practice the strategy, their performance should be closely monitored in order to provide corrective feedback (i.e., identify and praise aspects of strategy use performed correctly as well as identify and correct aspects in need of improvement). In addition to providing feedback, teachers provide cues and prompts about how to use the strategy. 
5. Using peer activities. Students can be placed into groups with each student assigned a part or step of the strategy to use on a mutual task. For example, when initially practicing the Paraphrasing Strategy, one student reads a paragraph, one student identifies the main idea, another the details, and a fourth puts the main idea and details into his or her own words. For the next paragraph, they switch roles and so on until all students perform each part of the strategy.

It is important to systematically fade the level of assistance provided to students to allow for more independent and self-directed practice. Once students show they can meet mastery criteria for practicing the strategy in materials for which the difficulty level has been controlled, they are ready to move to independent practice in more advanced materials (e.g., at grade level).

Give advanced practice. During this stage, students practice the strategy with more advanced tasks, materials, or both. Typically this means using the strategy with tasks similar to what students are required to do in their classrooms. This stage is designed to get students ready to generalize strategy use to situations outside the setting in which it was taught.

Using the Paraphrasing Strategy as an example, students would begin to practice the RAP steps on reading materials written at their grade level (vs. their actual reading level, which may be lower). These passages can come from a variety of sources, including textbooks students are currently using in one of their classes. It is possible that some students may have difficulty making the leap from reading level to grade-level text. If this is the case, it may be better to gradually increase the reading level of practice passages until students are using the strategy on grade level. For example, if a student is reading at the fourth-grade level and is in the ninth grade, the first round of practice might be in passages written at the sixth- or seventh-grade level.

As with the previous initial practice stage, supported and prompted practice is provided, such as close monitoring of student performance and corrective feedback. The support and feedback is withdrawn as quickly as possible so that students can perform the strategy independently at the end of this stage. To verify mastery of the strategy with authentic tasks, a posttest assessment is provided. When students reach mastery criterion, this achievement is acknowledged and celebrated. At this point, students are told that all their efforts to master the strategy may be for naught if they do not actually use it in other situations. For example:

\footnotetext{
You have worked incredibly hard on learning the Paraphrasing Strategy and are using it very effectively on the reading selections I have been giving you. Well done!
}

However, if you don't use the strategy in other settings, you won't get the maximum benefit of your hard work. Think of the strategy as a tool in your toolbox. If you don't take the tool out of the toolbox to use, it just gets rusty from not being used.

So what we need to do now is to work on generalizing the strategy. Who knows what generalizing means? Right, it means using the strategy in other situations and settings where it can help you read for understanding and memory. So how and where do you think generalizing the Paraphrasing Strategy will help you? Great answers!

Over the next few weeks we will do some things that will help you generalize using the strategy. Are you ready to commit to that? I am ready to commit to helping you, too.

Yoke the strategy to new situations. This final stage is designed to help students generalize strategy use to situations outside the training setting. The SIM program has developed phases of generalization instruction (Deshler et al., 1996) designed to help students:

1. discriminate when to use the strategy,

2. decide how the strategy can be used in different settings and situations,

3. use feedback to develop goals and plans to improve performance,

4. adapt the strategy to other tasks and academic demands, and

5. use the strategy and adaptations of the strategy across settings and times.

The first generalization phase, Orientation, is designed to make students aware of the need for applying the strategy across settings and tasks. This phase includes discussions about (a) rationales for using the strategy in other settings, (b) why generalization is important, (c) identifying settings and situations where they can use the strategy, (d) how they can remember to use the strategy, (e) how to use cue cards to help them use the strategy, (f) noticing cues that will signal the strategy should be used, and (g) deciding situations when the strategy is not appropriate to use. While these discussions are important for orienting students as to the why, where, and how of generalization, merely talking about strategy transfer is often insufficient for generalization to occur.

Thus the second phase of generalization, Activation, is designed to promote transfer by giving students specific assignments to use the strategy in a variety of settings (e.g., other classes, at home) and with a range of materials (e.g., textbooks, newspaper articles, manuals). Briefly, this phase includes giving assignments that require the student to use the strategy outside the training setting. For example, students can be given a homework assignment that requires them to select a newspaper or magazine article with which to use the Paraphrasing Strategy. The next day students meet with their teacher to give a brief oral report on the article content and answer a few questions about the main ideas and details contained the article. Students are also asked 
about how effective they thought the strategy was and how they used it. In addition, students can use a "Report of Strategy Use" form to record the date they used the strategy, the title of the reading, and where they used it. Along with specific assignments, several nonspecific assignments can be given whereby students choose the setting (e.g., in their science class) and reading selection, record strategy use, and schedule a short conference to discuss the topic and how well the strategy worked. During the Activation phase, students may begin to make modifications to the strategy steps, how they use them, or both. These personal modifications are acceptable (and often desirable) as long as the changes are effective. The Activation phase continues until the student has successfully completed four to six assignments on various types of readings in several different settings.

In the next phase, Adaptation, students are encouraged to identify the various cognitive components embedded in the strategy and how they might be used to perform other tasks. With teacher guidance, students revisit the strategy and identify and describe the cognitive components (e.g., chunking information, self-questioning, self-monitoring, paraphrasing) and discuss how these processes might be used across different settings and tasks. Additionally, they are helped to identify how a particular strategy might be modified to use with other tasks.

Using the Paraphrasing Strategy as an example, this phase might include discussions about how breaking up a large piece of information into smaller pieces (i.e., reading and paraphrasing one paragraph at a time) might be appropriate for approaching how to write an essay. Or how paraphrasing lecture content might be useful when taking notes and that the RAP strategy could be changed to LAP (i.e., Listen, Ask, Put).

The last stage, Maintenance, is used to ensure that students continue to use the strategy correctly over time. This stage is conducted by giving students strategy-use probes spread out over several months, usually beginning a week or two after the Activation stage. For the Paraphrasing Strategy, these probes would consist of a variety of readings presented to students for which they are required to apply the RAP steps. Their ability to perform the strategy steps is assessed and needed feedback given. In addition to these scheduled probes, students are encouraged to set goals for using the strategy, to self-monitor when they use the strategy, and to evaluate how well the strategy is working for them.

\section{INCORPORATING EXPLICIT INSTRUCTIONAL ELEMENTS IN LESSON DESIGN AND DELIVERY WHEN TEACHING A TASK-SPECIFIC LEARNING STRATEGY}

This next example illustrates how the instructional stages can be incorporated in a lesson format as well as makes clear how the EI elements identified earlier in this article are integrated into the lessons. For illustration purposes, the EDIT Strategy (Hughes, Schumaker, McNaughton, Deshler, \& Nolan, 2010), recently published through the KU-CRL, is used. As the name implies, this four-step strategy is designed to help students more effectively edit written products generated on a word processor, both for mechanical errors as well as for enhancing meaning.

The effectiveness of the EDIT strategy was evaluated by conducting a randomized control trial study with students with $\mathrm{LD}$ in both reading and written expression in grades 4 , 5, and 6 (Hughes \& Kubo, 2011). Effectiveness of the strategy was measured by examining the percentage of errors corrected on experimenter-generated passages embedded with 25 mechanical and meaning errors as well as the ratio of errors to total word count on passages generated by the students. Posttest results showed that students who learned the strategy corrected significantly more errors on the errorembedded passage ( $E S=.84$ ) as well as on rate of errors on their own written work $(E S=.87)$. Similar results were found for maintenance probes several weeks after treatment ended. Additionally, the treatment group s posttest scores on both measures were compared to the scores of 25 students nominated by their teachers as "average writers." No significant differences were found; students with LD using the strategy decreased their errors to the same level as the group of general education students.

\section{Steps of the Strategy}

The first step, Enter your first draft is simple and straightforward. Students, after applying any strategies they use to plan and organize their essay, enter text using a word processor. They are instructed not to spend a lot of time editing as they go, as this is an inefficient method and interrupts writing flow.

The second step, Do a spell check, teaches students how to more effectively use the spellcheckers that come with their word processors (e.g., select correct options provided, add additional letters if no options are presented, correct homophone errors, correct "wrong word-correct spelling" errors).

The third step, Interrogate yourself using the COPS questions, involves students asking themselves a series questions in order to detect and correct capitalization errors, overall appearance errors (e.g., problems with margins, indentations, and spacing), punctuation errors, and substance and meaning issues (e.g., incomplete sentences, missing words, and the need additional details). The last part of this step requires students to set a goal for adding more content (e.g., adding four detail sentences).

The final step, Type in corrections and run the spellchecker, instructs students to type in changes they made on the hard copy of their first draft and then run the spellchecker one 
more time in case errors were made when the changes were entered.

\section{Lesson Format for Teaching the EDIT Strategy}

The EDIT Strategy steps are taught starting with a pretest used to assess current ability to detect and correct errors as well as make additional substance changes. Following the pretest, five lessons are used to teach the strategy. Each lesson incorporates some or all of the EI elements (in italics):

Lesson One: In this lesson, the teacher shares pretest results with students and guides the discussion about why editing is important as well as brainstorms with students about why editing is difficult for them, the types of problems they encounter when editing, and any current strategies they use when editing. This discussion personalizes the relevance for learning a strategy to become better writers and editors beyond sharing pretest results whereby students are essentially told, "You have problems in editing and you need to learn an editing strategy." By exploring their experiencesboth positive and negative-in the editing process, students are more likely to see the need for learning new skills and thus are more motivated to make a commitment to learn the strategy. At the end of this lesson, the teacher provides a brief description of the strategy.

Lesson Two. In this second lesson, students learn and practice the first two steps of the EDIT strategy. Throughout this lesson the teacher requires high student involvement and responding by asking questions and through peer activities. Learning the first two steps before introducing the other steps is used to break down multiple-step strategies into more manageable chunks and reduces the load on working memory as the new material is being learned. The steps are taught using the sequence of describing and modeling using think-aloud protocols followed by providing supported and scaffolded practice by both reducing the number of steps practiced as well as having students practice the Spell step on passages which contain a range of possible spelling errors rather than on their own writing. This helps them focus on using the strategy versus having to think about composing their own essay at the same time.

Upon completion of each practice session, students are provided corrective feedback about what they did well and what parts of the strategy steps they need to do better. As part of this process, students set a goal about what they will do better on the next practice attempt. Students continue to practice until they have met a preset mastery criterion, at which time they move on to the next lesson.

Lesson Three. Lesson three begins with a review of the content presented in the previous lesson to verify that students remember the key aspects of the first two steps. Following the review, students are taught the last two steps of the strategy, again by providing clear descriptions and models of the IT steps of EDIT and requiring high rates of student responding. When practice begins, students not only practice the third and fourth steps of the strategy, they also practice the first and second steps, thus providing cumulative and distributed practice. To do so, students apply the strategy to a document containing errors in spelling, capitalization, overall appearance, and punctuation as well as incomplete sentences with missing words. Students apply the EDIT strategy to detect and correct the errors and are provided corrective feedback and set goals after each sheet is completed until mastery criterion is reached.

Lesson Four. In this lesson students practice memorizing the steps of the strategy with aid of the mnemonic devices EDIT and COPS as well as describing the purpose of each step and why it is important in their own words. Memorizing the steps to fluency will help them use the steps later when they begin to use the entire strategy on their own written work. This reduces the load on working memory, as they will not have to stop and think about which step should be used and what the step directs them to do, and thus they can focus their attention on the application of the strategy versus trying to recall the names of the steps. Being able to understand the purpose of each step and why it is important supports motivation to use the strategy and a deeper understanding of the underlying processes of the strategy. As with other lessons, this lesson begins with a review of the steps previously taught and practiced, activities to promote high levels of engagement and responding, corrective feedback, and mastery learning.

Lesson Five. In the last lesson, students begin to practice all elements of the strategy on their own written work (i.e., an essay written in response to a prompt). Up until now, they have been practicing the strategy on error-embedded passages provided by the teacher. In order provide more authentic practice, their own work is used as the medium for practicing the EDIT Strategy. Because they are now using their own written work, the self-regulation skills of setting goals and self-monitoring (i.e., adding additional content to their first draft) are introduced and modeled and then practiced along with the rest of the strategy steps and substeps. Students write essays and apply the entire strategy until mastery criteria (i.e., they have produced a paper that is $96 \%$ error free, and they have added at least four elaborations to their first draft).

Once mastery has been reached, a variety of activities are used to promote generalization and maintenance. These activities can include practicing the strategy on assignments completed in settings other than the instructional setting (e.g., other classes, home), requesting other teachers cue them to use the strategy, having them bring graded written assignments from other classrooms to jointly evaluate their 
use of the EDIT strategy and discuss any successes or difficulties, or having them self-monitor on a checklist whenand wherever they have used the EDIT strategy.

\section{SUMMARY}

Students with LD often do not use effective and efficient strategies when presented with academic tasks to complete. Thus, designing task-specific strategies that help them become more successful and independent learners has become an important curriculum component. However, in addition to designing logically constructed (and parsimonious) strategies, equivalent attention needs to be paid to how these strategies are taught in order to gain maximum benefits.

When examining the research on effective teaching procedures, EI procedures emerge as a necessary component of instruction for teaching students with LD to acquire and generalize academic skills, including task-specific learning strategies. It was the intent of this article to provide examples of how the elements of EI could be incorporated into the design and delivery of instruction needed to learn these critical strategies.

\section{REFERENCES}

Adams, G. L., \& Engelmann, S. (1996). Research on direction instruction: 25 years and beyond DISTAR. Seattle, WA: Educational Achievement Systems.

Archer, A. L, \& Hughes, C. A. (2011). Explicit Instruction: Effective and efficient teaching. New York: Guilford Press.

Berkeley, S. (2007). Reading comprehension instruction for students with learning disabilities. In T. Scruggs \& M. Mastropieri (Eds.), Advances in Learning and Behavioral Disabilities (Vo1. 20, pp. 79-99). London Elsevier.

Berry, G., Hall, D., \& Gildroy, P. G. (2004). Teaching learning strategies. In B. K. Lenz \& D. D. Deshler with B. R. Kissam (Eds.), Teaching Content to All (pp. 258-275). Boston, MA: Pearson.

Boyle, J. R. (2006). Learning from lectures: The implications of notetaking for students with learning disabilities. Learning Disabilities: A Multidisciplinary Journal, 14, 91-97.

Brophy, J., \& Good, T. (1986). Teacher behavior and student achievement. In M. C. Whittrock (Ed.), Handbook of research on teaching (3rd ed., pp. 328-377). New York: McMillan.

Deshler, D. D., Ellis, E. S., \& Lenz, B. K. (1996). Teaching adolescents with learning disabilities: Strategies and methods. Denver, CO: Love.

Deshler, D. D., Lenz, B. K., Bulgren, J., Schumaker, J. B., Davis, B., \& Grossen, B. (2004). Adolescents with disabilities in high school settings: Student characteristics and setting dynamics. Learning Disabilities: A Contemporary Joumal, 1, 30-48.

Deshler, D. D., Schumaker, J. B. (2006). High school students with disabilities: Strategies for accessing the curriculum. New York: Corwin Press.

Ellis, E. S., Deshler, D. D., Lenz. B. K., Schumaker, J. B., \& Clark, F. L. (1991). An instructional methodology for teaching learning strategies. Focus on Exceptional Children, 23, 1-24.

Ellis, E. S., \& Lenz, K. (1987). A component analysis of effective learning strategies for LD students. Learning Disabilities Focus, 2, $94-107$.
Ellis, E. S. \& Worthington, L. (1994). Research synthesis on effective teaching principles and the design of quality tools for educators. Washington, DC: Special Education Programs (ED/OSERS). (ERIC Document Reproduction Service No. ED386853)

Gersten, R., Beckmann, S., Clarke, B., Foegen, A., Marsh, L., Star, J. R., et al. (2009). Assisting students struggling with mathematics: Response to intervention (RtI) for elementary and middle schools (NCEE No. 2009-4060). Washington, DC: National Center for Education Evaluation and Regional Assistance, Institute of Education Sciences, US Department of Education. Available online at ies.ed.gov/ncee/wwc/publication/practiceguides

Gersten, R., Fuchs, L. S., Williams, J, P., \& Baker, S. (2001). Teaching reading comprehension strategies to students with learning disabilities: A review of research. Review of Educational Research, 71(2), 279-320.

Gersten R., Williams, J. P., Fuchs, L., \& Baker, S., Koppenhaver, D., Spadorcia, S., \& Harrison, M. (1998). Improving reading comprehension for children with disabilities: A review of research. Final report. Washington, DC: Special Education Programs (ED/ OSERS). (ERIC Document Reproduction Service No. ED451650)

Graham, S.. \& Harris, K. R. (2003) Students with learning disabilities and process of writing: A meta-analysis of SRSD studies. In H. L. Swanson, K. R. Harris, \& S. Graham (Eds.), Handbook of learning disabilities (pp. 323-344). New York: Guilford Press.

Harris, K. R, Graham, S., Mason, L. H., \& Friedlander, B. (2008). Powerful writing strategies for all students. Baltimore: Brookes.

Hattie, J. (2009). Visible learning: A synthesis of over 800 meta-analyses relating to achievement. New York: Routledge.

Hughes, C. A. (1996). Memory and test-taking strategies. In D. Deshler, E. Ellis, \& K. Lenz (Eds.), Teaching adolescents with learning disabilities: Strategies and methods (pp. 209-266). Denver, CO: Love.

Hughes, C.A., \& Kubo, M. (2011). The effectiveness of an editing strategy for middle school students with learning disabilities. Unpublished manuscript.

\section{STATEMENT OF OWNERSHIP, MANAGEMENT AND CIRCULATION}

Date of Filing: October 31, 2011

Title of Publication: Focus on Exceptional Children

Frequency of Issue: Monthly (except June, July \& August)

Location of Known Office of Publication: 9101 E. Kenyon Ave., Suite 2200, Denver.

CO 80237
Location of Headquarters of Publisher: 9101 E. Kenyon Ave., Suite 2200, Denver, CO 80237

Name and Address of Publisher, Editor, and Managing Editor: Stanley F. Love, 9101 E. Kenyon Ave., Suite 2200, Denver, CO 80237

Owner: Love Publishing Company

Extent and Nature of Circulation: World Wide Academic

$\begin{array}{cc}\begin{array}{c}\text { Average No. Copies } \\ \text { Each Issue During } \\ \text { Preceding } 12 \text { Months } \\ 1300\end{array} & \begin{array}{c}\text { Single Issue } \\ \text { Nearest } \\ \text { Filing Date } \\ 1300\end{array} \\ 70 & \\ 1006 & 50 \\ 45 & 1006 \\ 1121 & 30 \\ 35 & 1086 \\ 80 & 19 \\ 1236 & 52 \\ 64 & 1157 \\ 1300 & 143 \\ & 1300\end{array}$

Total No. Copies Printed

Paid Circulation

Sales through Dealers, etc.

Mail Subscriptions

Other Classes Mailed Through USPS

Total Paid Circulation

Free Distribution Outside the Mail

Total Free or Nominal Rate Distribution

Total Distribution

Office Use and Left Over

Total

1300

I certify that the statements made by me above are correct and complete. 


\section{rocus on Exceptional children}

Hughes, C. A., Ruhl, K. L., Schumaker, J. B., \& Deshler, D. D. (1995). The assignment completion strategy. Lawrence, KS: EDGE Enterprises.

Hughes, C. A., Ruhl, K. L., Schumaker, J. B., \& Deshler, D. D. (2002). Effects of instruction in an assignment completion strategy on the homework performance of students with learning disabilities in general education classes. Learning Disabilities Research and Practice, 17, 1-18.

Hughes, C. A., Schumaker, J. B., McNaughton, D., Deshler, D. D., \& Nolan, S. M. (2010). The EDIT strategy. Lawrence: University of Kansas.

Hughes, C. A., \& Suritsky, S. K. (1994). Note taking skills of university students with and without learning disabilities. Journal of Learning Disabilities, 27, 20-24.

Kamil, M. L., Borman, G. D., Dole, J., Kral, C. C., Salinger, T., \& Torgesen, J. (2008). Improving adolescent literacy: Effective classroom and intervention practices: A practice guide (NCEE \#2008-4027). Washington, DC: National Center for Education Evaluation and Regional Assistance, Institute of Education Sciences, US Department of Education. Retrieved from http://ies.ed.gov/ncee/wwc

Kroesbergen, E. H., \& Van Luit, J. E. H. (2003). Mathematics interventions for children with special needs: A meta-analysis. Remedial and Special Education, 24, 97-114.

Lenz, B. K, Ellis, E. S., \& Scanlon, D. (1996). Teaching learning strategies to adolescents and adults with learning disabilities. Austin, TX: Pro-Ed.

Luke, S. D. (2006). The Power of Strategy Instruction. Evidence for Education, 1, 1-11. Washington, DC: National Dissemination Center for Children with Disabilities.

Mastropieri, M. A., Scruggs, T. E., Bakken, J. P., \& Whedon, C. (1996). Reading comprehension: A synthesis of research in learning disabilities. In T. E. Scruggs \& M. A. Mastropieri (Eds.), Advances in learning and behavioral disabilities (Vol. 10B, pp. 201-227). Greenwich, CT: JAI Press.

Miller, S. P. (1996). Perspectives on mathematics instruction. In D Deshler, E. Ellis, \& B. Lenz (Eds,), Teaching adolescents with learning disabilities: Strategies and methods (pp. 313-367), Denver, $\mathrm{CO}$ : Love.
Montague, M. (2008). Self-regulation strategies to improve mathematical problem solving for students with learning disabilities. Learning Disability Quarterly, 31(1), 37-44.

National Mathematics Advisory Panel. (2008). Foundations for success: The final report of the national mathematics advisory Panel. Washington, DC: US Department of Education.

Reid, R., \& Lienemann, T. O. (2006). Strategy instruction for students with learning disabilities. New York: Guilford Press.

Suritsky, S. K., \& Hughes, C. A. (1996). Note taking strategies. In D. Deshler, E. Ellis, \& B. Lenz (Eds.), Teaching adolescents with learning disabilities: Strategies and methods (pp. 266-312). Denver, CO: Love.

Swanson, H. L. (1999). Instructional components that predict treatment outcomes for students with learning disabilities: Support for a combined strategy and direct instruction model. Learning Disabilities Research and Practice, 14(3), 129-140.

Swanson, H. L. (2001). Searching for the best model for instructing students with learning disabilities. Focus on Exceptional Children, 34(2), 1-14.

Swanson, H. L., \& Hoskyn, M. (1998). A synthesis of experimental intervention literature for students with learning disabilities: A meta-analysis of treatment outcomes. Review of Educational Research, 68, 277-321.

Swanson, H. L., \& Saez, L. (2003). Memory difficulties in children and adults with learning disabilities. In H. L. Swanson, K. Harris, \& S. Graham (Eds.), Handbook of learning disabilities (p. 182-198). New York: Guilford Press.

Swanson, H. L. \& Siegel, L. (2001). Learning disabilities as a working memory deficit. Issues in Education: Contributions of Educational Psychology, 7(1), 1-48.

Therrien, W. J., Hughes, C. A., Kapelski, C., \& Mokhtari, K. (2009), Effectiveness of an essay test-taking strategy on students' with learning disabilities performance on persuasive essays. Journal of Learning Disabilities, 42(1), 14-23.

Vaughn, S., Gersten, R., \& Chard, D. J. (2000). The underlying message in LD intervention research: Findings from research syntheses. Exceptional Children, 67(1), 99-114.

\section{PERMISSIONS AND COPYRIGHT}

All rights are reserved. No part of this publication may be reproduced, photocopied, faxed, stored in a retrieval system, or transmitted in any form or by any means, electronic, mechanical, recording or otherwise, without the prior written permission of the publisher.
Back issues are available for sale. Reproduction requires permission and payment of fees. It is illegal and a violation of federal copyright law to reproduce this publication without permission. Direct all inquiries to the permissions editor. 